\title{
Relocalization of Cathepsin D and Cytochrome c Early in Apoptosis Revealed by Immunoelectron Microscopy
}

\author{
Karin Roberg \\ Division of Pathology II, Faculty of Health Sciences, Linköping University, Linköping, Sweden
}

\begin{abstract}
SUMMARY: Cathepsin D was translocated from lysosomal structures to the cytosol in primary cultures of neonatal rat cardiomyocytes exposed to oxidative stress, and these cells underwent apoptotic death during subsequent incubation. Temporal aspects of cathepsin D relocalization, cytochrome $c$ release, and decrease in mitochondrial transmembrane potential $\left(\Delta \psi_{\mathrm{m}}\right)$ were studied in myocytes exposed to the redox-cycling xenobiotic naphthazarin (5,8-dihydroxy-1,4-naphthoquinone). Immunofluorescence labeling revealed that cathepsin $D$ was translocated to the cytosol after 30 minutes of naphthazarin treatment, and cytochrome c was released from mitochondria to the cytosol after 2 hours. Western blotting and immunoelectron microscopy indicated a minor release of cytochrome c after only 30 minutes and 1 hour, respectively. Thereafter, a decrease in $\Delta \psi_{\mathrm{m}}$ was detected using the $\Delta \psi_{\mathrm{m}}$-sensitive dye $\mathrm{JC}-1$ and confocal microscopy, and ultrastructural analysis indicated apoptotic morphology. Pretreatment of the cultures with the cathepsin D inhibitor pepstatin A prevented release of cytochrome $c$ from mitochondria and maintained the $\Delta \psi_{\mathrm{m}}$. Moreover, ultrastructural examination showed no apoptotic morphology. These findings suggest that lysosomal destabilization (detected as the release of cathepsin $D$ ) and release of cytochrome $c$ from mitochondria take place early in apoptosis. Also, the former event probably occurs before the latter during apoptosis induced by oxidative stress because pretreatment with pepstatin A prevented release of cytochrome $\mathrm{c}$ and loss of $\Delta \psi_{\mathrm{m}}$ in cardiomyocytes exposed to naphthazarin. (Lab Invest 2001, 81:149-158).
\end{abstract}

$A$ poptosis occurs through activation of a cell suicide process that is regulated by many different intracellular and extracellular signals (Steller, 1995). Stress, hormones, viral infections, and the binding of ligands to the TNF family receptors are a few examples of well-studied apoptosis-inducing factors. Apoptosis involves a number of morphological features, such as cell shrinkage, chromatin condensation, nuclear fragmentation, and the formation of apoptotic bodies. Biochemical characteristics of apoptosis include changes in the mitochondria, such as the release of cytochrome c (Skulachev, 1998) and the loss of mitochondria transmembrane potential (Kroemer et al, 1997; Zamzami et al, 1995), together with activation of the caspase cascade. Cytochrome $c$ is a nuclear, DNA-encoded protein that is found in the intermembrane space and on the surface of the inner membrane in mitochondria. Release of this protein from mitochondria to the cytosol is an important occurrence in apoptosis which allows complexation of cytochrome $\mathrm{c}$ with cytosolic apoptosis protein-activating factor 1 (Apaf-1), which, in the presence of deoxyadenosine triphosphate (dATP) or ATP, can lead to activation of procaspase 9 (Cai et al, 1998). Microinjection of cytochrome $\mathrm{c}$ into several different types of cells

Received August 28, 2000.

This study was supported by the Swedish Cancer Foundation (grant 2703), Östgöta regionens Cancer Foundation at Linköping University, and Östergötlands läns landsting.

Address reprint requests to: Dr. Karin Roberg, Division of Pathology II, Faculty of Health Sciences, Linköping University, S-58185 Linköping, Sweden.E-mail: karin.roberg@pat.liu.se has been found to induce apoptosis through a caspase-dependent pathway ( $\mathrm{Li}$ et al, 1997; Zhivotovsky et al, 1998).

Naphthazarin, a structural analog of the anticancer drug adriamycin, is metabolized to its semiquinone form by intracellular reductases and then reoxidized in a redox cycle that produces superoxide radicals. Current evidence suggests that increased oxidative stress plays an important role in mediating the cardiotoxicity of adriamycin (Singal et al, 1997), and it has been proposed that adriamycin-induced cell death in cardiomyocytes involves both apoptosis and necrosis (Kumar et al, 1999). Apoptotic death of cardiomyocytes may be involved in several heart disorders, among others, myocardial infarction and congestive heart failure. Narula and coworkers (1999) studied human cardiomyopathy and found that cytochrome $\mathrm{c}$ accumulates in the cytosol of cardiomyocytes and that this event is followed by caspase activation and cleavage of protein kinase $\mathrm{C}$ but not of poly(ADP-ribose) polymerase.

Until recently, little attention has been focused on the participation of lysosomes and lysosomal enzymes in the apoptotic process. However, Wu et al (1998) have observed that the level of cathepsin D increased in lymphoid cells during adriamycininduced apoptosis and also that apoptosis was blocked by pepstatin $A$, which is known to inhibit aspartic proteases, such as cathepsin D, renin, and pepsin (Shields et al, 1991). Cathepsin D is a lysosomal aspartic protease that is present in practically all animal cells, often in relatively high concentrations (Yamamoto, 1995). This enzyme degrades proteins at low $\mathrm{pH}$ and is believed to play important roles in 
protein catabolism, antigen-processing (Peters et al, 1991), protein targeting (Cantor and Kornfeld, 1992), and the progression of breast cancer (Rochefort et al, 1996). Using immunocytochemistry and electron microscopy, our research group (Roberg and Öllinger, 1998a) has previously found that treatment of cardiomyocytes with naphthazarin caused early translocation of cathepsin D from lysosomal structures to the cytosol, resulting in apoptotic cell death. In other experiments (Roberg et al, 1999), we observed that the release of cytochrome $c$ preceded early relocalization of cathepsin D in fibroblasts exposed to oxidative stress.

The aim of the present investigation was to determine the ultrastructural location of cathepsin D and cytochrome $\mathrm{c}$ in cardiomyocytes exposed to oxidative stress, and to further investigate the participation of lysosomal enzymes in apoptosis, in particular regarding their relationship to events involving the mitochondria. A pre-embedding immunocytochemical method was used for ultrastructural analysis of cathepsin D and cytochrome $\mathrm{c}$ in the myocytes. In combination with ultra-small gold probes and subsequent silver enhancement, that technique has been shown to achieve sensitive detection of intracellular proteins in cultured cells (Roberg and Öllinger, 1998b).

\section{Results}

\section{Location of Cathepsin D during Exposure to Naphthazarin}

Immunofluorescence analysis revealed substantial granular staining of control myocytes, indicating the presence of cathepsin D in lysosomes (Fig. 1A). After exposure to naphthazarin for 30 minutes, most of the myocytes exhibited diffuse staining of cathepsin D, implying translocation of the enzyme from lysosomes to the cytosol (Fig. 1B). Electron microscopic immunocytochemistry confirmed that cathepsin $D$ was present in the lysosomes in control cells (Fig. 2, A and $\mathrm{B})$ at different magnification and was relocalized in a time-dependent manner in myocytes treated with naphthazarin (Fig. 2, C and D).

\section{Location of Cytochrome c during Exposure to Naphthazarin}

At a light microscopic level, control cells stained with monoclonal antibodies against cytochrome $c$ displayed a characteristic mitochondrial pattern (Fig. 3A). This pattern did not change after treatment with naphthazarin for 30 minutes (Fig. 3B), whereas after 2 hours the myocytes were diffusely stained and some of the mitochondria had changed shape (Fig. 3C). However, at the electron microscopic level, silver-enhanced gold particles labeling cytochrome $\mathrm{c}$ were observed in the cytosol after exposure to naphthazarin for 1 hour (Fig. 4C); after 3 hours, the amount of cytochrome $\mathrm{c}$ in the cytosol increased considerably, although a majority of the particles were found surrounding the mitochondria (Fig. 4D).

In both control and naphthazarin-treated cardiomyocytes, the particles labeling cytochrome c were detected around the outer mitochondrial membrane. Presumably, with the pre-embedding immunocytochemistry technique, the primary antibodies are only able to penetrate the outer mitochondrial membrane, and, because the distance between the antigen and the gold probe on the secondary antibody can be up to $20 \mathrm{~nm}$, the mitochondria are labeled on the outer membrane. However, specific staining can be seen in the control cells in Figure 4A, and the specificity of the method at higher magnification is clearly demonstrated by Figure 4B.
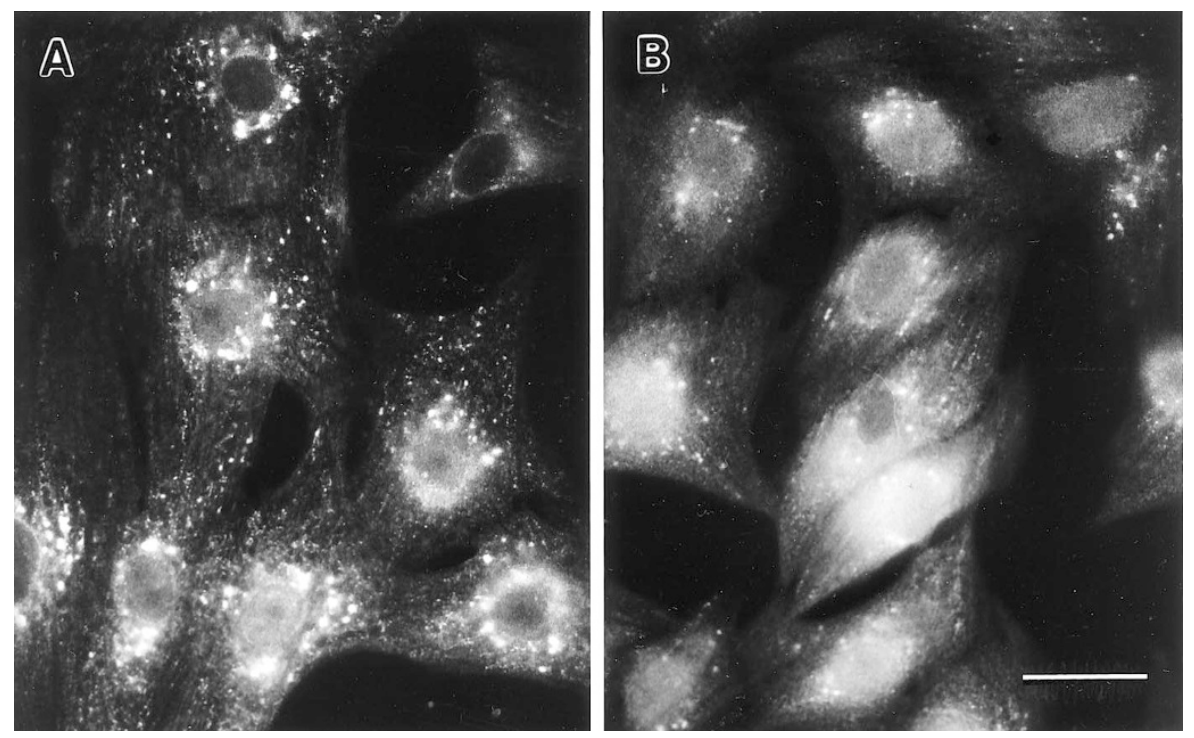

\section{Figure 1.}

Immunofluorescence detection of cathepsin D in rat cardiomyocytes. The micrographs show control cells (A) and cells exposed to $1.5 \mu \mathrm{m}$ naphthazarin for 30 minutes (B). Relocalization of cathepsin D can be seen in the treated cells. Bar $=30 \mu \mathrm{m}$. 

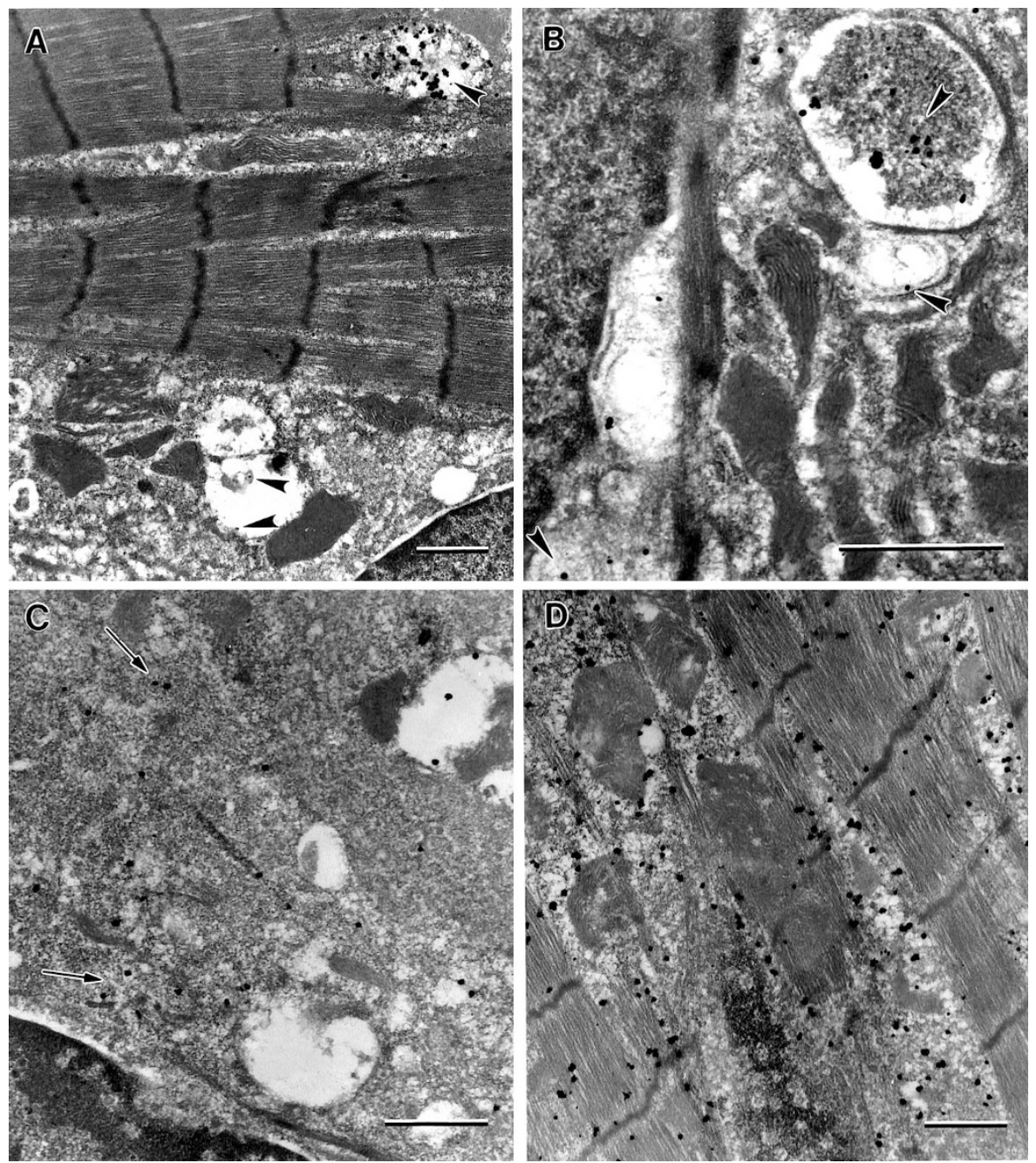

Figure 2.

Electron micrographs of typical rat cardiomyocytes subjected to immunocytochemistry of cathepsin D using antibodies tagged with ultra-small gold particles and subsequent silver enhancement. Silver-enhanced gold particles can be seen in lysosomelike structures (arrowheads) in control cells (A and B), but they are spread throughout the cytosol (arrows) in cells exposed to $1.5 \mu \mathrm{m}$ naphthazarin for 1 hour (C) and 3 hours (D), respectively. Bar $=1 \mu \mathrm{m}$.

\section{Importance of Cathepsin D in Apoptosis Induced by Oxidative Stress}

Early ultrastructural signs of apoptosis, such as reduced cell size and condensed chromatin and mitochondria, were observed after 3 hours of naphthazarin exposure (compare $A$ and $B$ in Fig. 5), but were not seen in myocytes pretreated with pepstatin $A$, a specific inhibitor of cathepsin D (compare $C$ and D in Fig. 5). Moreover, light microscopy revealed that the cathepsin D inhibitor significantly prevented apoptotic morphology, quantified by counting pyknotic nuclei in Giemsa-stained cells (Fig. 6).

Furthermore, immunocytochemistry and electron microscopy of cells pretreated with pepstatin A showed that, after exposure to naphthazarin for 1 hour, cathepsin D was present in the cytosol (Fig. 7A), whereas after 5 hours, cytochrome $c$ was still in the immediate vicinity of the mitochondria (Fig. 7B).

To confirm these results, cytosolic fractions of control and naphthazarin-treated cells were subjected to Western blot analysis (Fig. 7C), which showed that release of cytochrome c occurred after 30 minutes and became more marked after 2 hours (these findings are supported by the data shown in Figs. 3 and 4). However, almost no cytochrome c was liberated from pepstatin-A-pretreated myocytes exposed to naphthazarin for 3 hours.

\section{Mitochondrial Membrane Potential during Oxidative Stress}

The lipophilic cationic probe $\mathrm{JC}-1$ was used to measure the $\Delta \psi_{\mathrm{m}}$. This probe has a monomer that emits light at $527 \mathrm{~nm}$ after excitation at $490 \mathrm{~nm}$, and it can selectively enter mitochondria. Depending on the membrane potential, JC-1 can form J-aggregates that are associated with a large shift in emission to $590 \mathrm{~nm}$. Accordingly, the fluorescence changes from green at depolarized membrane potentials (positive to -100 $\mathrm{mV}$ ) to orange-red at hyperpolarized potentials (more negative than $-140 \mathrm{mV}$ ) (Chen and Smiley, 1993; Reers et al, 1991). After 2 hours of naphthazarin exposure, the first cells with decreased $\Delta \psi_{\mathrm{m}}$ were 

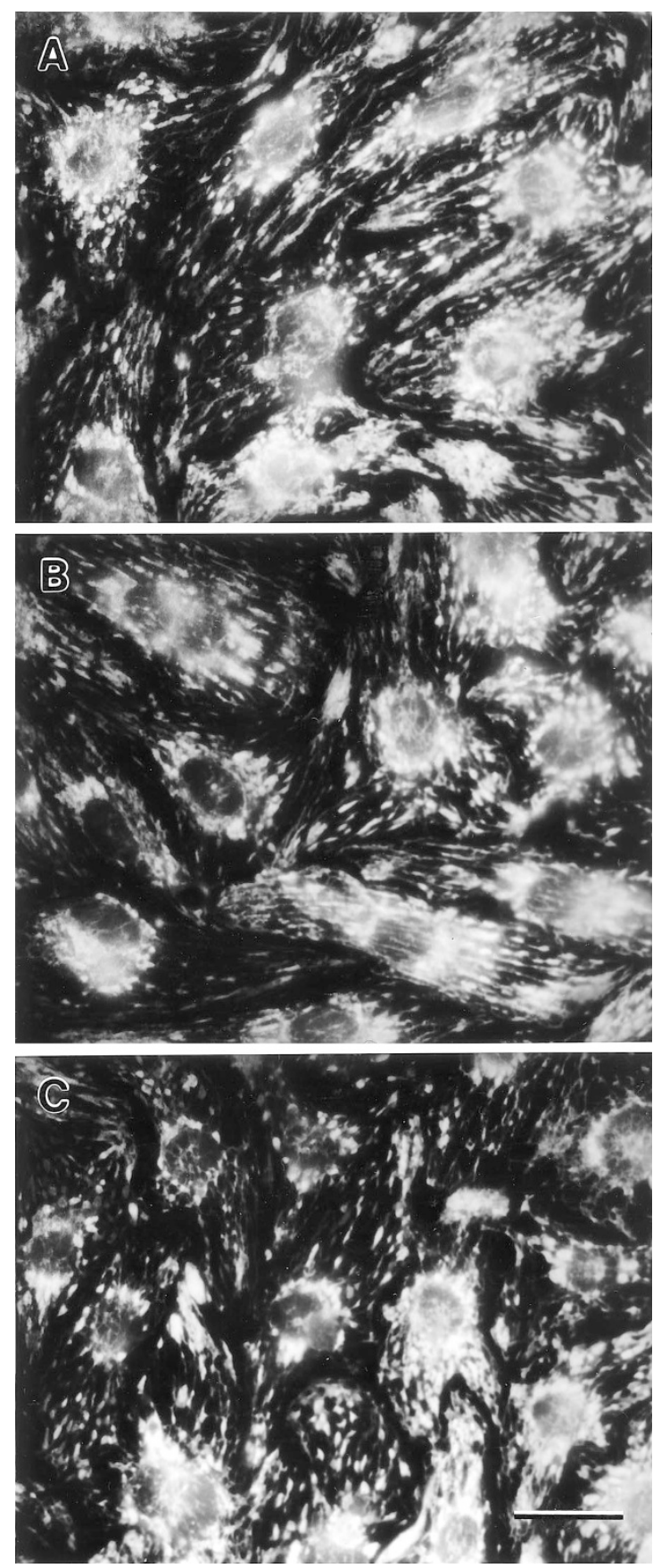

Figure 3.

Immunofluorescence detection of cytochrome $\mathrm{c}$ in rat cardiomyocytes. The micrographs show control cells (A) and cells exposed to $1.5 \mu \mathrm{m}$ naphthazarin for 30 minutes (B) and 2 hours (C). Bar $=30 \mu \mathrm{m}$.

observed in the confocal microscope. In cells pretreated with pepstatin A before naphthazarin exposure, a significantly smaller number of cells showed decreased $\Delta \psi_{\mathrm{m}}$ (Fig. 8).

\section{Discussion}

\section{Location of Cathepsin D and Cytochrome $c$ during Oxidative Stress}

An association between apoptosis and translocation of cytochrome $\mathrm{c}$ from the intermembrane space of the mitochondria to the cytosol has been shown in a number of studies. Many authors have reported that such relocalization occurs in several cell systems after exposure to various stimuli and also that cytochrome $c$ induces apoptosis when added to cell-free extracts (Liu et al, 1996). The exact mechanisms of mitochondrial cytochrome $\mathrm{c}$ release are not known, although there is increasing evidence that members of the $\mathrm{Bcl}-2$ protein family play an important role in this process. Overexpression of $\mathrm{Bcl}-2$ and $\mathrm{Bcl}-\mathrm{xL}$ protects mitochondria and inhibits liberation of cytochrome c (Kharbanda et al, 1997), whereas pro-apoptotic members of the family, such as Bid and Bax, are believed to induce formation of pores in the mitochondrial membrane and thereby participate in the release of cytochrome $c$ (Desagher et al, 1999). Release of cytochrome c during apoptosis has been shown mainly by Western blotting or immunofluorescence techniques, and only a few investigators have used immunocytochemistry and electron microscopy to determine the exact location of this hemoprotein. Notwithstanding, in the ultrastructural studies of the location of cytochrome c during apoptosis that are available in the literature, only a single or a limited population of mitochondria was analyzed at one time point in irradiated U-937 cells (Kharbanda et al, 1997) and in human myocytes obtained after cardiomyopathy (Narula et al, 1999). In the present investigation, the location of cytochrome $c$ was determined at different times during apoptosis using three different techniques, and the temporal aspects of the release of cathepsin $D$ and cytochrome c from their respective organelles during the progression of apoptosis were also examined.

After 30 minutes of exposure to naphthazarin (Fig. 1), immunofluorescence showed a clear relocalization of cathepsin D, but not cytochrome c (Fig. 3). However, Western blotting and immunocytochemistry at an electron microscopic level revealed a limited release of cytochrome $\mathrm{c}$ after naphthazarin treatment for 30 minutes and 1 hour, respectively. All of the methods used to detect cytochrome $\mathrm{c}$ showed that it was released from the mitochondria in cardiomyocytes exposed to oxidative stress, although the time at which the relocalization was first observed varied. After 3 hours of exposure, Western blotting and electron microscopy (EM) showed an increased amount of cytochrome $\mathrm{c}$ in the cytosol, but there were still particles labeling cytochrome $\mathrm{c}$ around the outer membrane of most of the mitochondria (Fig. 4D). By comparison, in a study of apoptosis in sheets of granulosa cells cultured for 72 hours without gonadotropic support (D'Herde et al, 2000), the cells were found to exhibit one subset of normal-sized mitochondria that contained cytochrome $c$ and a second subset of smaller mitochondria that lacked functional cytochrome c; these subsets were ultrastructurally localized by oxidation of diaminobenzidine tetrahydrochloride. Moreover, in experiments on cardiomyocytes exposed to $\mathrm{H}_{2} \mathrm{O}_{2}$ (Cook et al, 1999), release of mitochondrial cytochrome $\mathrm{c}$ was shown within 15 to 30 minutes, and this was accompanied by a drop in $\Delta \psi_{\mathrm{m}}$ that was partially restored after 1 hour. Our research 

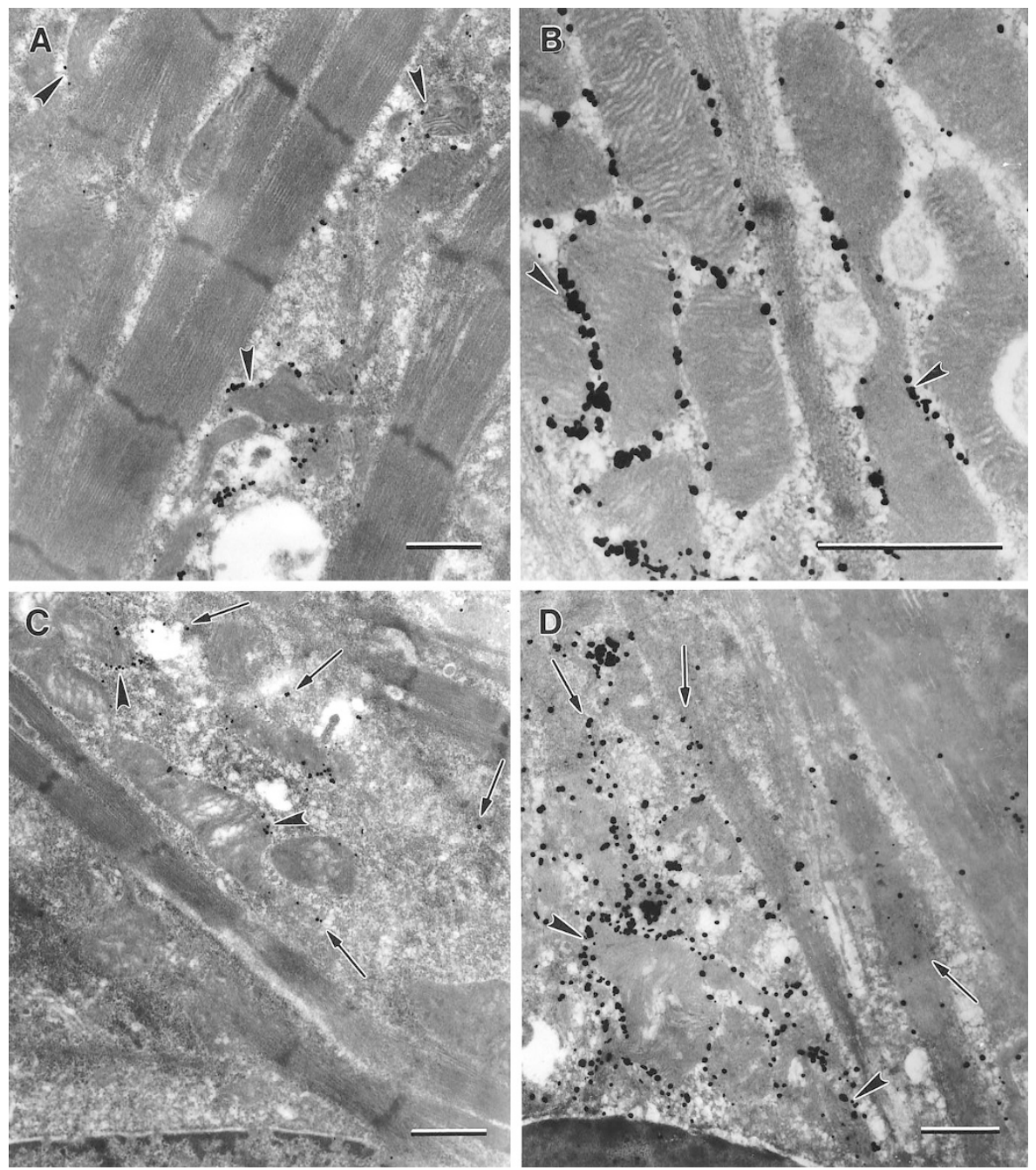

\section{Figure 4.}

Electron micrographs of typical rat cardiomyocytes subjected to immunocytochemistry of cytochrome $\mathrm{c}$ using antibodies tagged with ultra-small gold particles and subsequent silver enhancement. The micrographs show control cells ( $A$ and B) and cells treated with $1.5 \mu \mathrm{m}$ naphthazarin for 1 hour (C) and 3 hours (D), respectively. Silver-enhanced gold particles are seen on the outer mitochondrial membrane (arrowheads) in both control and treated cells, but only in the treated cells are some silver-gold particles also spread throughout the cytosol (arrows). Bar $=1 \mu \mathrm{m}$.

team has previously observed a similar course of events in fibroblasts exposed to oxidative stress (Roberg et al, 1999), and we propose that the early loss of $\Delta \psi_{\mathrm{m}}$ leads to the release of a small amount of cytochrome c soon after the onset of apoptosis induced by oxidative stress. In the present experiments, after 3 hours of treatment with naphthazarin, there was more extensive relocalization of cytochrome $\mathrm{c}$, and about $20 \%$ of the cells showed decreased $\Delta \psi_{\mathrm{m}}$. This sizable release of cytochrome $c$ might have been due to opening of the mitochondrial permeability transition pores.

\section{The Role of Cathepsin D in Apoptosis Induced by Oxidative Stress}

In previous studies in our laboratory, pretreatment with pepstatin A was found to inhibit apoptotic morphology in fibroblasts (Roberg et al, 1999) and in cardiomyocytes up to 48 hours (Öllinger, 2000) after naphthazarin exposure. Furthermore, in the latter cells, activation of caspase-3-like caspases was detected after 6 hours, and this was also inhibited by pretreatment with pepstatin A (Öllinger, 2000). In addition, other investigators using HeLa cells with cathepsin D antisense RNA (Deiss et al, 1996) and cathepsin D-/- fibroblasts (Wu et al, 1998) have found a lower frequency of apoptotic cell death after exposing the cells to known apoptosis-inducing stimuli.

In the present experiments, inhibition of cathepsin D prevented both the release of cytochrome $\mathrm{c}$ from mitochondria and a decrease in mitochondrial $\Delta \psi_{\mathrm{m}}$, two events that are necessary for apoptosis. Similarly, in one of our previous study, inhibition of cathepsin D in fibroblasts prevented a decrease in intracellular ATP. However, in the cardiomyocytes, inhibition of cathepsin $D$ did not prevent relocalization of this protein (Fig. 7A), indicating that the lysosomes were affected by oxidative stress. Thus, active cathepsin D seems to be involved in mediating the apoptotic signal 

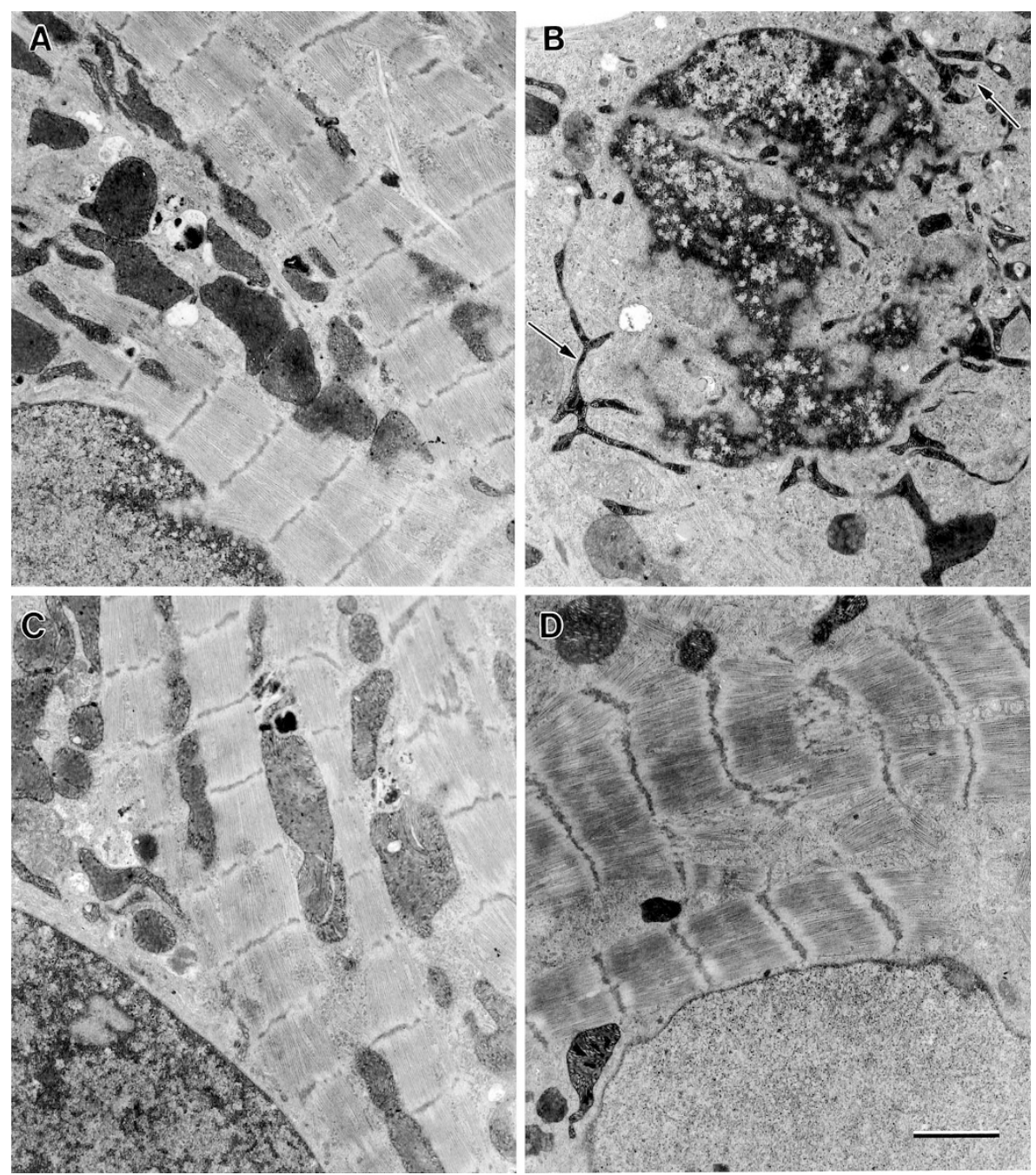

Figure 5.

Electron micrographs of rat cardiomyocytes, non-pretreated or pretreated with pepstatin $A$ and then exposed to naphthazarin. The micrographs show a control cell (A), a cell exposed to $1.5 \mu \mathrm{m}$ naphthazarin for 3 hours (B), a cell only pretreated with pepstatin $A(C)$, and a cell pretreated with pepstatin $A$ and then exposed to $1.5 \mu \mathrm{m}$ naphthazarin for 3 hours (D). Note condensed morphology of the mitochondria (arrows) in the cell treated solely with naphthazarin (B). Bar $=1 \mu \mathrm{m}$.

to the mitochondria in this system. No experimental data have been reported that show a direct effect of cathepsin $\mathrm{D}$ and other lysosomal enzymes on the mitochondrial membrane, and it is likely that one or more substrates participate in the apoptotic reaction pathway comprising the release of lysosomal enzymes and mitochondrial events. Cathepsin D cleaves next to a hydrophobic group; hence, it is probably incapable of directly activating caspases (Yamamoto, 1995). Some investigators have suggested that the lysosomal cysteine proteases cathepsin $B$ and $L$ are involved in the apoptotic process (Isahara et al, 1999; Shibata et al, 1998) and that they activate procaspases (Ishisaka et al, 1998; Vancompernolle et al, 1998). However, cathepsin $\mathrm{D}$ seems to be important during apoptosis induced by oxidative stress in fibroblasts and cardiomyocytes, but its target is unknown and this needs to be further elucidated.

In summary, important incidents in the mitochondria, such as the release of cytochrome $c$ and the loss of $\Delta \psi_{\mathrm{m}}$, were inhibited by pretreatment with pepstatin

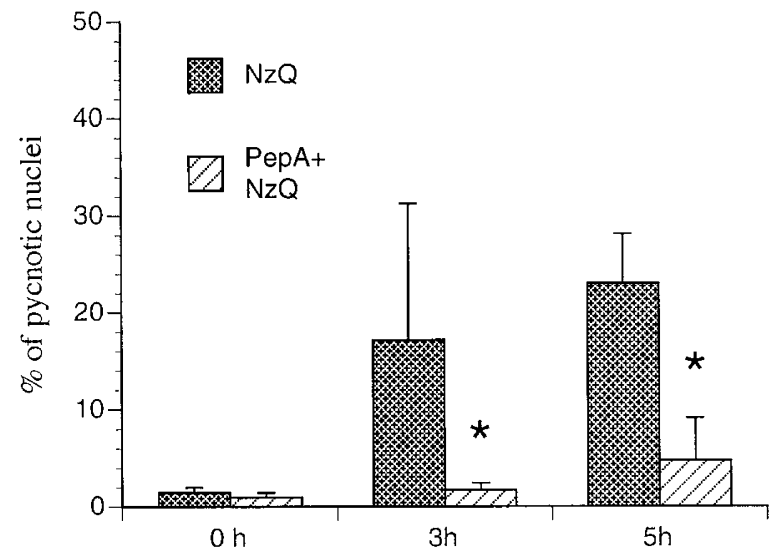

Figure 6.

Analysis of pyknotic nuclei in Giemsa-stained rat cardiomyocytes exposed to $1.5 \mu \mathrm{M}$ naphthazarin. Pretreatment with $100 \mu \mathrm{M}$ pepstatin A was initiated 24 hours before exposure to naphthazarin. Values are means $\pm \mathrm{sD}, n=4$. Cells pretreated with pepstatin A before being subjected to oxidative stress (exposure to naphthazarin) differed significantly from cells exposed solely to oxidative stress as calculated by the Mann-Whitney $U$ test. ${ }^{*} p \leq 0.05$. 

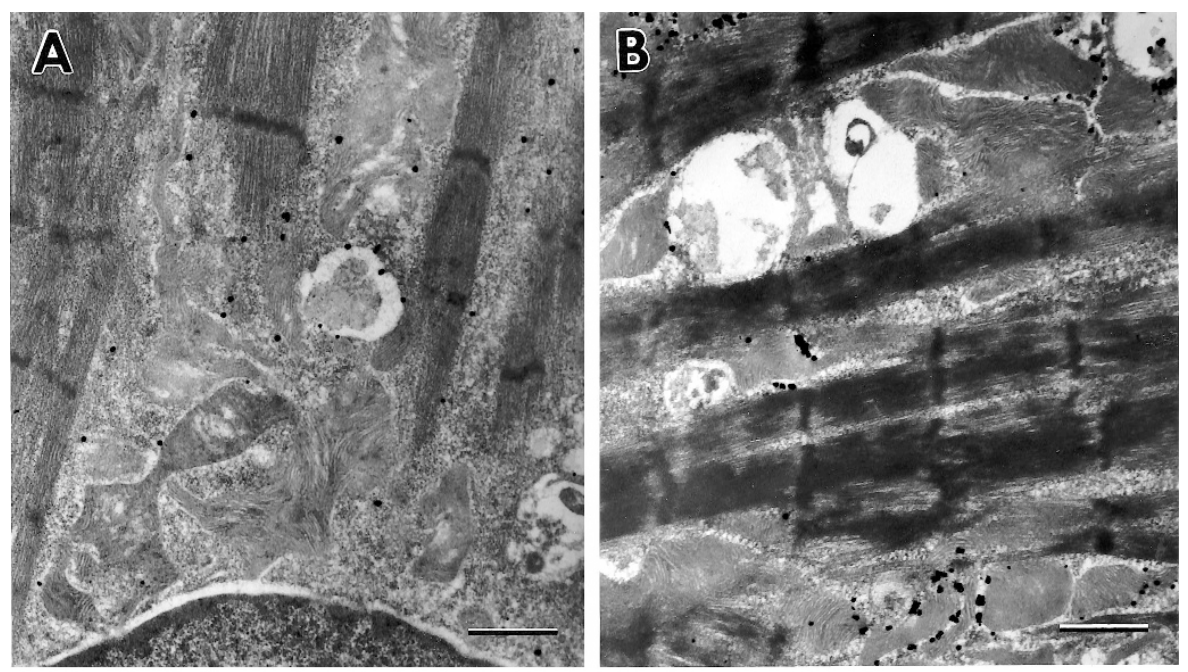

C

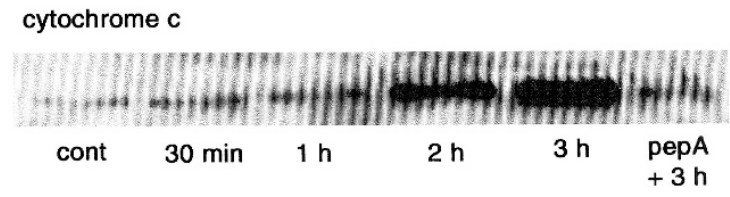

Figure 7.

Electron microscopy (prepared as in Fig. 2) and Western blot analysis of rat cardiomyocytes pretreated with $100 \mu \mathrm{M}$ pepstatin A for 24 hours before exposure to oxidative stress (naphthazarin). The micrographs show the location of cathepsin $D(A)$ and cytochrome $c(B)$ in pepstatin-A-pretreated cells exposed to naphthazarin for 1 hour and 5 hours, respectively. Notice that cathepsin D was relocalized, but not cytochrome $\mathrm{c}$. The Western blot shows cytochrome $\mathrm{c}$ in cytosolic fractions from control cells and cells exposed to naphthazarin for different amounts of time. Bar $=1 \mu \mathrm{m}$.

A. This indicates that lysosomes and lysosomal enzymes are necessary for the onset of apoptosis induced by oxidative stress. Furthermore, lysosomal destabilization was observed, detected as a release of cathepsin $D$, suggesting that this is an essential early event in apoptosis and that it occurs "upstream of" the release of mitochondrial cytochrome $\mathrm{c}$.

\section{Materials and Methods}

\section{Preparation of Cardiomyocytes}

Hearts from 2- to 3-day-old male and female SpragueDawley rats were digested in $\mathrm{Ca}^{2+}$ - and $\mathrm{Mg}^{2+}$-free Hank's buffer (GIBCO, Paisley, United Kingdom) supplemented with $0.5 \mathrm{mg} / \mathrm{ml}$ collagenase I (Worthington, Freehold, New Jersey), as previously described (Öllinger and Brunmark, 1994). Cells were resuspended in Eagle's minimum essential medium supplemented with $10 \%$ dialyzed calf serum, $50 \mathrm{lU} / \mathrm{ml}$ penicillin, and $50 \mathrm{mg} / \mathrm{ml}$ streptomycin and were then plated at a density of 100,000 cells $/ \mathrm{cm}^{2}$ in culture dishes (Costar, Cambridge, Massachusetts) previously coated with $5.0 \mu \mathrm{g}$ of type I collagen $/ \mathrm{cm}^{2}$ (Boehringer, Mannheim, Germany). The cells were subsequently cultured at $37^{\circ} \mathrm{C}$ in an atmosphere of $5 \% \mathrm{CO}_{2}$ and $95 \%$ air. After 24 hours, the medium was changed to culture medium containing cytosine- $\beta$-Darabinofuranoside $(10 \mu \mathrm{g} / \mathrm{ml})$ to inhibit the growth of fibroblasts; this medium was changed every other day. Cytosine- $\beta-D$-arabinofuranoside was omitted the day before experiments without any detectable increase in the number of fibroblasts.

\section{Exposure to Oxidative Stress}

Naphthazarin (5,8-dihydroxy-1,4-naphthoquinone; Aldrich Chemie, Steinheim, Germany) was dissolved in ethanol (stock solution $2.0 \mathrm{~mm}$ ) and added to 5- to 7-day-old cultures in prewarmed Eagle's minimum essential medium supplemented with $2 \mathrm{~mm}$ glutamine, and the cultures were subsequently incubated at $37^{\circ} \mathrm{C}$. The concentration of naphthazarin $(1.5 \mu \mathrm{M})$ was carefully selected to avoid necrotic cell death.

Pepstatin A (100 $\mu \mathrm{m}$; Sigma, St. Louis, Missouri) was dissolved in water-free dimethyl sulfoxide (DMSO) and added to complete cell culture medium at $37^{\circ} \mathrm{C}$ (final DMSO concentration, $0.4 \%$ ). A fresh stock solution of pepstatin A $(25 \mathrm{~mm})$ was prepared every day. Treatment of myocytes with pepstatin A (added in culture medium) was initiated 24 hours before exposure to naphthazarin. For light microscopy, round glass coverslips (diameter, $22 \mathrm{~mm}$ ) were placed in the culture dishes before cell plating.

\section{Detection of Apoptotic Morphology}

Cardiomyocytes were fixed in $4 \%$ phosphate-buffered formaldehyde, stained with a $5 \%$ Giemsa solution (Merck, Darmstadt, Germany), and examined in a light 


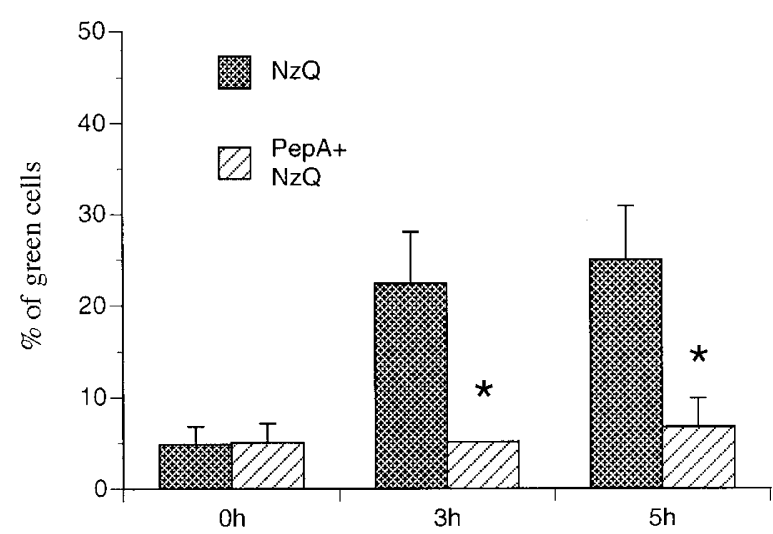

Figure 8.

JC-1 vital staining of rat cardiomyocytes exposed to oxidative stress. Nonpretreated and pepstatin-A-pretreated $(100 \mu \mathrm{M})$ cells were exposed to $1.5 \mu \mathrm{M}$ naphthazarin for various amounts of time and then stained with $5 \mu \mathrm{g} / \mathrm{ml} \mathrm{JC}-1$ for 10 minutes. Mitochondria are green $\left(\Delta \psi_{\mathrm{m} m}<-100 \mathrm{mV}\right)$ and orange-red $\left(\Delta \psi_{\mathrm{m} m}>-140 \mathrm{mV}\right)$ in control cells but only green in cells with a decreased $\Delta \psi_{\mathrm{m}}$. Cells containing green or red/green mitochondria were counted, and the illustrated values are means $\pm \mathrm{SD}, n=4$ (500 cells/sample). Cells pretreated with pepstatin $A$ and then subjected to naphthazarin differed significantly from cells exposed solely to naphthazarin, as calculated by the Mann-Whitney $U$ test. ${ }^{*} p \leq 0.05$.

microscope. Cells displaying pyknotic nuclei were considered to be apoptotic. However, it was difficult to determine whether apoptosis had actually occurred because the deaths of individual myocytes were not synchronized; several cells detected as apoptotic at early time points might have later ruptured as a result of secondary necrosis. The trypan blue dye exclusion test was used to study plasma membrane integrity. Stained (dead) and unstained (viable or apoptotic) cells were counted in each culture, using an inverted microscope at low magnification $(\times 250)$. The trypan blue method showed that membrane integrity was lost in $7 \%$ of the cells after 5 hours of exposure to naphthazarin (data not shown).

Cultures to be subjected to transmission electron microscopy were prepared as previously described (Brunk et al, 1995). Briefly, cardiomyocytes in situ in the plastic culture dishes were fixed by adding $2 \%$ glutaraldehyde in $0.1 \mathrm{M}$ sucrose-sodium cacodylate$\mathrm{HCl}$ buffer ( $\mathrm{pH}$ 7.2) and post-fixed in osmium (Johnson Matthey Chemicals, Roystone, United Kingdom). Dehydration, followed by en bloc staining with uranyl acetate, dehydration, and embedding in Epon-812 was also performed in the culture dishes. Thin sections of the cured blocks were cut with a diamond knife, stained with lead citrate, and then examined and photographed in a JEOL 1200-EX electron microscope (Tokyo, Japan) at $80 \mathrm{kV}$.

\section{Immunofluorescence Detection of Cathepsin D and Cytochrome c}

Cardiomyocytes grown on coverslips were fixed in 4\% paraformaldehyde (Fluka AG, Buchs, Switzerland) in Dulbecco's phosphate-buffered saline (PBS) for 20 minutes at $4^{\circ} \mathrm{C}$ and then processed for immunocytochemistry as described earlier (Brunk et al, 1997).
Briefly, the cells were incubated with a polyclonal rabbit antihuman cathepsin D antibody (dilution 1:100; Dakopatts, Älvsjö, Sweden), followed by a goatantirabbit immunoglobulin G (lgG) Texas Red conjugate (dilution 1:200; Vector Laboratories, Burlingame, California) or a monoclonal mouse-antihuman cytochrome c antibody, clone 6H2.B4 (dilution 1:50; Pharmingen, San Diego, California), and subsequently a mouse anti-lgG Texas Red conjugate (dilution 1:50; Calbiochem, San Diego, California). Thereafter, the cells were rinsed in PBS and distilled water, mounted in Vectashield $₫$ Mounting Medium (Vector Laboratories), and examined and photographed in a Nikon photo microscope, using green exciting light and a red barrier filter. Controls incubated without anticathepsin D antibodies or anticytochrome $\mathrm{c}$ antibodies did not stain.

The specificity of the polyclonal rabbit antihuman cathepsin D antibody was determined by Western blotting on a $12 \%$ SDS-PAGE gel. A major band detected at $30 \mathrm{kDa}$ was interpreted as the heavy chain of the two-subunit form of cathepsin D, and a minor band at $48 \mathrm{kDa}$ was considered to be single-chain precathepsin D (Deiss et al, 1996).

\section{Immunogold Labeling of Cathepsin D and Cytochrome c}

Antibodies coupled to ultra-small gold particles were used to visualize cathepsin D and cytochrome c, as described elsewhere (Roberg and Öllinger, 1998b). In short, myocytes were fixed for 20 minutes at $4^{\circ} \mathrm{C}$ in a solution consisting of $4 \%$ paraformaldehyde and $0.05 \%$ glutaraldehyde (Agar Scientific, Essex, United Kingdom) in $0.15 \mathrm{M}$ sodium cacodylate buffer ( $\mathrm{pH} 7.6)$. The cultures were then immersed in a freshly prepared solution of $0.05 \%$ saponin and $1 \%$ glycine in PBS. Next, the cells were incubated with polyclonal rabbit antihuman cathepsin D antibodies (dilution 1:100) or monoclonal mouse antihuman cytochrome $\mathrm{c}$ antibodies (dilution 1:50) overnight at $4^{\circ} \mathrm{C}$. Thereafter, the cells were rinsed and incubated with goat or mouse anti-IgG antibodies tagged with 0.8-nm gold particles (dilution 1:100; Aurion, Wageningen, The Netherlands) overnight at $4^{\circ} \mathrm{C}$. The immunogold-labeled cells were fixed for 10 minutes in $2.5 \%$ glutaraldehyde in PBS, rinsed in PBS at room temperature, and finally silver enhanced for 6 minutes at $26^{\circ} \mathrm{C}$, as described by Lah et al (1990). Control cells, in which the primary antibody had been excluded or replaced with an immunoglobulin fraction of nonimmune rabbit serum, remained unstained (Roberg and Öllinger, 1998b). Cultures were embedded in Epon-812, and sections of immunogold-labeled myocytes were examined in a JEOL 1200-EX electron microscope at $80 \mathrm{kV}$.

\section{Analysis of $\Delta \psi_{m}$}

A $1 \mathrm{mg} / \mathrm{ml}$ stock solution of JC-1 (5,5', 6,6'tetrachloro-1,1', 3,3'-tetraethyl-benzimidazolcarbocyanine iodide; Molecular Probes, Eugene, Oregon) was made up in DMSO. Fresh staining solution (5 $\mu \mathrm{g} / \mathrm{ml}$ ) was prepared in culture medium and was 
subsequently added to the dishes, which were kept in the dark at room temperature for 10 minutes and then rinsed twice in PBS. For confocal microscopy, a coverslip was removed from a Petri dish and inverted in PBS on a microculture slide. Images were obtained using a $488 \mathrm{~nm}$ argon laser in an LSM 410 confocal microscope (Zeiss, Jena, Germany). Microscopy was performed using a green channel (with a 515-560-nm bandpass filter) and a red fluorescence channel (with a 590-nm barrier filter). A 63×/1.4 Plan-Fluotar (Zeiss, Jena, Germany) objective was used for high-resolution confocal images. Mitochondria appear as a mixture of green $(\Delta \psi \mathrm{m}<-100 \mathrm{mV})$ and orange-red $\left(\Delta \psi_{\mathrm{m}}>\right.$ $-140 \mathrm{mV}$ ) structures in control cells, but are almost all green in cells with a decreased $\Delta \psi_{\mathrm{m}}$. To analyze the number of cells with a decreased $\Delta \psi_{\mathrm{m}}$, at least 500 cells containing green or red/green mitochondria were counted in each sample.

\section{Western Blotting of Cytochrome c}

To obtain cytosolic fractions from cardiomyocytes, the cells in one Petri dish were scraped loose with a rubber policeman into $250 \mu \mathrm{l}$ of PBS at $4^{\circ} \mathrm{C}$. Sucrose (500 mm) diluted in PBS was quickly added under continuous vortexing, and the cells were pelleted by centrifugation for 60 seconds at $14,000 \times g$ and $4^{\circ} \mathrm{C}$. The protein in the supernatant was precipitated in $5 \%$ TCA and pelleted, and then resuspended in $63 \mathrm{~mm}$ Tris-HCl (pH 6.8), $6 \mathrm{M}$ urea, 10\% glycerol, 2\% SDS, 5\% 2-mercaptoethanol, and $0.05 \%$ bromphenol blue. The protein concentration was determined, and $30-\mu \mathrm{g}$ aliquots of the cell lysate were fractionated by $15 \%$ SDS-PAGE. The proteins were subsequently transferred onto a nitrocellulose membrane that was incubated in a blocking solution (5\% skimmed milk and $0.1 \%$ Tween-20 in $50 \mathrm{~mm}$ Tris buffer supplemented with $0.15 \mathrm{M} \mathrm{NaCl}$ [TBS]) for 1.5 hours at room temperature and then washed in TBS. Thereafter, the membranes were treated with a mouse antihuman cytochrome c monoclonal antibody, clone $7 \mathrm{H} 8.2 \mathrm{C} 12$ (1:500; Pharmingen), diluted with $0.1 \%$ skimmed milk and $0.05 \%$ Tween-20 in TBS. Membranes were washed and incubated for 1 hour at room temperature with peroxidase-conjugated goat antimouse (1:1500; Dakopatts, Älvsjö, Sweden), and the bands were visualized by enhanced chemiluminescence (Amersham Pharmacia Biotech, Buckinghamshire, England).

\section{Statistical Analysis}

All experiments were repeated three to five times. Results are given as arithmetic means \pm SD. Statistical significance was calculated using the Mann-Whitney $U$ test. A $p$ value $\leq 0.05$ was considered significant.

\section{References}

Brunk UT, Dalen H, Roberg K, and Hellqvist HB (1997). Photo-oxidative disruption of lysosomal membranes causes apoptosis of cultured human fibroblasts. Free Radic Biol Med 23:616-626.
Brunk UT, Zhang H, Roberg K, and Öllinger K (1995). Lethal hydrogen peroxide toxicity involves lysosomal iron-catalyzed reactions with membrane damage. Redox Rep 1:267-277.

Cai J, Yang J, and Jones DP (1998). Mitochondrial control of apoptosis: The role of cytochrome c. Biochim Biophys Acta 1366:139-149.

Cantor AB and Kornfeld S (1992). Phosphorylation of Asnlinked oligosaccharides located at novel sites on the lysosomal enzyme cathepsin D. J Biol Chem 267:23357-23363.

Chen LB and Smiley ST (1993). Probing mitochondrial membrane potential in living cells by a J-aggregate-forming dye. In: Manson WT, editor. Fluorescent and luminescent probes for biological activity. London: London Academic, 124-132.

Cook SA, Sugden PH, and Clerk A (1999). Regulation of bcl-2 family proteins during development and in response to oxidative stress in cardiac myocytes: Association with changes in mitochondrial membrane potential. Circ Res 85:940-949.

Deiss LP, Galinka H, Barissi H, Cohen O, and Kimichi A (1996). Cathepsin D protease mediates programmed cell death induced by interferon-gamma, Fas/APO-1 and TNFalpha. EMBO J 15:3861-3870.

Desagher S, Osen-Sand A, Nichols A, Eskes R, Montessuit S, Lauper S, Maundrell K, Antonsson B, and Martinou JC (1999). Bid-induced conformational change of Bax is responsible for mitochondrial cytochrome $\mathrm{c}$ release during apoptosis. J Cell Biol 144:891-901.

D'Herde KD, De Prest B, Mussche S, Schotte P, Beyaert R, Van Coster R, and Roels F (2000). Ultrastructural localization of cytochrome $\mathrm{c}$ in apoptosis demonstrates mitochondrial heterogenity. Cell Death Differ 7:331-337.

Isahara K, Ohsawa Y, Kanamori S, Shibata M, Waguri S, Sato N, Gotow T, Watanabe T, Momoi T, Urase K, Kominami E, and Uchiyama $Y$ (1999). Regulation of a novel pathway for cell death by lysosomal aspartic and cysteine proteinases. Neuroscience 91:233-249.

Ishisaka R, Utsumi T, Yabuki M, Kanno T, Furuno T, Inoue M, and Utsumi K (1998). Activation of caspase-3-like protease by digitonin-treated lysosomes. FEBS Lett 435:233-236.

Kharbanda S, Pandey P, Schofield L, Israels S, Roncinske R, Yoshida K, Bharti A, Yuan ZM, Saxena S, Weichselbaum R, Nalin C, and Kufe D (1997). Role for Bcl-xL as an inhibitor of cytosolic cytochrome $\mathrm{C}$ accumulation in DNA damageinduced apoptosis. Proc Natl Acad Sci USA 94:6939-6942.

Kroemer G, Zamzami N, and Susin SA (1997). Mitochondrial control of apoptosis. Immunol Today 18:44-51.

Kumar D, Kirshenbaum L, Li T, Danelisen I, and Singal P (1999). Apoptosis in isolated adult cardiomyocytes exposed to adriamycin. Ann N Y Acad Sci 874:156-168.

Lah JJ, Hayes DM, and Burry RW (1990). A neutral pH silver development method for the visualization of 1-nanometer gold particles in pre-embedding electron microscopic. J Histochem Cytochem 38:503-508.

Li F, Srinivasan A, Wang Y, Armstrong RC, Tomaselli KJ, and Fritz LC (1997). Cell-specific induction of apoptosis by microinjection of cytochrome c. Bcl-xL has activity independent of cytochrome c release. J Biol Chem 272:30299-30305.

Liu X, Kim CN, Yang J, Jemmerson R, and Wang X (1996). Induction of apoptotic program in cell-free extracts: Requirement for dATP and cytochrome c. Cell 86:147-157. 
Narula J, Pandey P, Arbustini E, Haider N, Narula N, Kolodgie FD, Dal Bello B, Semigran MJ, Bielsa-Masdeu A, Dec GW, Israels S, Ballester M, Virmani R, Saxena S, and Kharbanda S (1999). Apoptosis in heart failure: Release of cytochrome c from mitochondria and activation of caspase-3 in human cardiomyopathy. Proc Natl Acad Sci USA 96:8144-8149.

Öllinger K (2000). Inhibition of cathepsin D prevents freeradical-induced apoptosis in rat cardiomyocytes. Arch Biochem Biophys 373:346-351

Öllinger K and Brunmark A (1994). Effect of different oxygen pressures and $\mathrm{N}, \mathrm{N}^{\prime}$-diphenyl-p-phenylenediamine on adriamycin toxicity to cultured neonatal rat heart myocytes. Biochem Pharmacol 48:1707-1715.

Peters PJ, Neefjes JJ, Oorschot V, Ploegh HL, and Geuze HJ (1991). Segregation of MHC class II molecules from MHC class I molecules in the Golgi complex for transport to lysosomal compartments. Nature 349:669-676.

Reers M, Smith TW, and Chen LB (1991). J-aggregate formation of a carbocyanine as a quantitative fluorescent indicator of membrane potential. Biochem 30:4480-4486.

Roberg K, Johansson U, and Öllinger K (1999). Lysosomal release of cathepsin $D$ precedes relocation of cytochrome $c$ and loss of mitochondrial transmembrane potential during apoptosis induced by oxidative stress. Free Radic Biol Med 27:1228-1237.

Roberg K and Öllinger K (1998a). Oxidative stress causes relocation of the lysosomal enzyme cathepsin $D$ with ensuing apoptosis in neonatal rat cardiomyocytes. Am J Pathol 152:1151-1156.

Roberg K and Öllinger K (1998b). A pre-embedding technique for immunocytochemical visualization of cathepsin $D$ in cultured cells subjected to oxidative stress. J Histochem Cytochem 46:411-418.

Rochefort H, Liaudet E, and Garcia M (1996). Alterations and role of human cathepsin $D$ in cancer metastasis. Enzyme Protein 49:106-116.

Shibata M, Kanamori S, Isahara K, Ohsawa Y, Konishi A, Kametaka S, Watanabe T, Ebisu S, Ishido K, Kominami E, and Uchiyama $Y$ (1998). Participation of cathepsins B and D in apoptosis of PC12 cells following serum deprivation. Biochem Biophys Res Commun 251:199-203.
Shields PP, Gonzales TA, Charles D, Gilligan JP, and Stern W (1991). Accumulation of pepstatin in cultured endothelial cells and its effect on endothelial processing. Biochem Biophys Res Commun 177:1006-1012.

Singal PK, lliskovic N, Li T, and Kumar D (1997). Adriamycin cardiomyopathy: Pathophysiology and prevention. FASEB J 11:931-936.

Skulachev VP (1998). Cytochrome c in the apoptotic and antioxidant cascades. FEBS Lett 423:275-280.

Steller H (1995). Mechanisms and genes of cellular suicide. Science 267:1445-1449.

Vancompernolle K, Van Herreweghe F, Pynaert G, Van de Craen M, De Vos K, Totty N, Sterling A, Fiers W, Vandenabeele P, and Grooten J (1998). Atractyloside-induced release of cathepsin B, a protease with caspase-processing activity. FEBS Lett 438:150-158.

Wu GS, Saftig P, Peters C, and El-Deiry WS (1998). Potential role for cathepsin $D$ in p53-dependent tumor suppression and chemosensitivity. Oncogene 16:2177-2183.

Yamamoto K (1995). Cathepsin E and cathepsin D: Biosynthesis, processing and subcellular location. In: Takahashi K, editor. Aspartic proteinases: Structure, function, biology and biomedical implications. New York: Plenum Press, 223-229.

Zamzami N, Marchetti P, Castedo M, Zanin C, Vayssiere JL, Petit PX, and Kroemer G (1995). Reduction in mitochondrial potential constitutes an early irreversible step of programmed lymphocyte death in vivo. J Exp Med 181:16611672.

Zhivotovsky B, Orrenius S, Brustugun OT, and Doskeland SO (1998). Injected cytochrome c induces apoptosis. Nature 391:449-450. 